\title{
AUSÊNCIAS E PRESENÇAS PARA UMA CARTA DE STEPHEN MACKENNA
}

\section{Caetano Waldrigues Galindo}

\author{
Letter writing is the only device for \\ combining solitude with good company \\ (Byron) \\ I'm like a mirror; I'm nothing till you look \\ at me \\ (Mark Sandman)
}

\section{Cartas ausentes, presentes}

Na peça Arcadia, de Tom Stoppard, que lida com dois momentos temporais diferentes e, entre outras coisas (fractais, entropia, determinismo, morte...), com um enigma da biografia de Lord Byron, um dos personagens, Bernard Nightingale, professor universitário, acredita ter descoberto um significante fato novo na vida do poeta, que explicaria, inclusive, sua primeira saída da Inglaterra. Depois de toda sua investigação, no entanto, ele descobre apenas indícios circunstanciais, que apontam para a possibilidade de que o fato tenha ocorrido, talvez mesmo para sua probabilidade.

Mas não uma prova.

Angustiado diante de um problema tão constante para quem tenta reconstruir vidas passadas, ele em um momento lembra que a prova, a confissão de Byron, pode mesmo ter sido escrita - em uma carta, digamos, que depois de lida, ou não, terá sido queimada ou perdida.

Num momento posterior da peça veremos até outro personagem receber uma carta de Byron e queimá-la antes de sequer aberta.

A probabilidade de Nightingale.

Mas essa carta queimada não tinha que ver com o fato que o professor queria comprovar. Sabe disso o espectador, privilegiado, que também sabe que, na versão apresentada pela peça, Byron realmente (como o Byron de fato) não participou daquele duelo e não matou aquele homem.

Mas o que resta como reflexão ali sobre biografia e epistolografia serve para nos lembrar da efemeridade do registro, das inúmeras possibilidades eliminadas por não terem sido, cujos registros podem ter igualmente sido descartados. 
Cartas são voláteis.

Nem sempre destinadas ao armazenamento e, mais ainda, raramente disponibilizadas a olhos outros.

Em 1919, por exemplo, Stephen Mackenna [1872-1934], até hoje o grande tradutor de Plotino para o inglês, escreveu uma longa carta a seu editor (e protetor, digamos assim) Ernest Debenham, um rico industrial com interesses por filosofia, que sete anos antes havia lido sua tradução de Sobre a beleza (primeiro trecho das Enéadas que MacKenna publicou, como livreto independente) e lhe escrevera uma carta em que detalhava seu interesse por patrocinar uma edição de toda a obra, traduzida por MacKenna.

Nesta carta, ele delineava sua poética de tradução. Seus princípios gerais e aqueles que a lida com o texto de Plotino lhe havia fornecido.

Carta, aquele texto se destinava apenas a Debenham. Me seria inacessível, nãodestinatário.

Em 1937, no entanto, logo depois da morte de MacKenna, E. R. (Eric Robertson) Dodds, acadêmico irlandês que no final da vida de MacKenna teve certo contato com ele, publica o Journal and letters of Stephen Mackenna, que vem prefaciado pelo escritor Padraic Colum e introduzido por uma memória, escrita pelo próprio Dodds, em que ele, em quase cem páginas, relata um resumo da vida do tradutor e de seus contatos com ele, e ela.

O livro, desnecessário dizer, está há muito tempo fora de catálogo. Inacessível para mim, por exemplo. "Carta queimada".

E a carta continuava lá.

É claro que, durante todo esse tempo, MacKenna e seu Plotino continuaram alcançando seus destinos.

A tradução das Enéadas, que lhe custou mais de vinte anos de um trabalho árduo, em nada facilitado pelas circunstâncias de sua vida e, igualmente, pelo contexto político irlandês que viveu (culminando com o Levante da Páscoa, de 1916, e a guerra civil de 1922), ainda está à venda, e continua sendo considerada um verdadeiro monumento da tradução da língua grega para o inglês. 
Quando, em 1997-2000, desenvolvi um trabalho de mestrado que se serviu pesadamente de um dos livros das Enéadas (como influência para a obra de Santo Agostinho) tive o prazer de poder contar com a possibilidade, em Curitiba, décadas depois, do diálogo com Plotino através de MacKenna. Mas dados sobre ele, por exemplo, continuavam difíceis de se obter.

E eles continuam raros mesmo hoje, no mundo do Google e da Wikipédia. Tradutores, afinal, nunca foram o centro do debate intelectual, embora tenham mais de uma vez podido possibilitar suas existências: de centro e debate.

MacKenna segue paradoxalmente presente como texto e ausente como homem.

Esse paradoxo se vê curiosamente realçado pelo uso que James Joyce pôde fazer de figuras reais da Dublin de seu tempo no Ulysses.

O livro de Dodds sobre MacKenna, afinal, tem prefácio de Colum, e nele aparecem citados AE (George William Russell), John Eglinton (William Kirkpatrick Magee), Richard Irvine Best e George Moore, todos eles (todos eles) citados por nomes e pseudônimos apenas em um episódio do Ulysses, a longa cena em que na Biblioteca Nacional de Dublin discutem-se teorias sobre o Hamlet, e em que MacKenna aparece como dedicado leitor e divulgador de Mallarmé ${ }^{1}$.

O mais curioso, ainda, é que se Magee e Russell, por exemplo, fazem parte da conversa de que participa Stephen Dedalus naquela cena, tanto Dodds quanto MacKenna, as presenças mais diretas para este nosso texto, aparecem apenas in absentia durante a discussão. Citados como autoridades ou referências.

Presentes conquanto ausentes ainda.

E na medida em que o Ulysses se transformava em um clássico incontornável do cânone moderno, MacKenna, que aos poucos ia sumindo como presença direta, ia-se imortalizando como personagem menor do romance.

Mas toda essa seqüência de ausências possibilitáveis via presenças posteriores (Debenham, Dodds, Joyce) ainda teve um novo desdobramento, do ponto de vista deste trabalho, quando o University Library Project, ligado à Universidade Carnegie Mellon, digitalizou e disponibilizou o livro de Dodds e, com ele, claro, a carta de 1919.

\footnotetext{
${ }^{1}$ Algo que, em 1904, data em que se passa a ação do romance de Joyce, não era tão comum no mundo anglófono como o seria hoje. Esse mesmo interesse de MacKenna pela vanguarda poética o levaria a buscar tudo que pôde encontrar da obra de Gerard Manley Hopkins ainda antes da publicação de sua poesia, que apenas viria a público em 1918, na edição inaugural a cargo de seu amigo Robert Bridges, que então era o poet laureate do Reino Unido.
} 
A carta perdida do Byron de Stoppard pode não ter existido e poderia, se encontrada, reconstituída, afinal não tratar do que se esperava. Mas a carta de Mackenna, agora, depois de quase um século, finalmente chega a mais um destinatário e, assim, pode chegar a este texto. Que, se algum interesse tiver, há de o todo derivar dela.

\section{Ausências e presenças, cartas}

Uma carta é uma réplica.

Na precisa e mesma medida em que toda enunciação o seja. E é. Uma carta é participar de um discurso, de uma troca de respostas, uma correspondência. Uma carta portanto é uma reação. E como toda reação ela de saída não pode presumir a solidão efetiva. Abro uma carta endereçando-a alguém. Abro uma carta endereçada a mim.

Uma carta é um discurso para alguém.

Mas aquele destinatário, e de fato gerador de minha resposta, moto original e destino final de minha fala, está por definição ausente, ou não seria necessária a carta. E por ausente, tem de se tornar mais presente, e de uma maneira mais incontornável. Cabe apenas ao autor da carta a criação da presença do destinatário ausente.

Uma carta é algo poderoso.

É simultaneamente interagir com um segundo enunciador que não pode interagir comigo e, mais ainda do que isso, instituir sua presença como contra-discurso e como meta discursiva. Converso com você, que não está; converso portanto com a imagem de você que crio e instrumento a partir de você, a partir de qualquer contato que possamos encenar, a partir, na maioria das vezes, de uma correspondência prévia.

Escrever cartas é a combinação mais poderosa da mais necessária e profunda solidão (escrever é por definição uma tarefa concentrada e isolada) com a mais definidora companhia. Não existe linguagem em solidão efetiva, não existe réplica isolada. E no isolamento que o autor da carta cria ele não apenas se vê confrontado, desafiado e provocado por esse fato, como tem de se ver inspirado a suplantar essa sua individualidade substituindo-a por uma profunda imersão na personalidade, no discurso daquele outro ausente que corporifica.

Uma carta só é um "bilhete numa garrafa” quando pronta. 
No insignificante período entre sua conclusão (sua primeira morte) e sua leitura (segundo nascimento). Neste, fora da garrafa, ela é fala. Naquele, antes dela, nada tem de mensagem a-quem-interessar-possa. Sob-medida, personalizada, ela é diálogo presente com a ausência que a define.

Se a linguagem, como queria Wittgenstein, é de fato um jogo, uma partida de xadrez, basta lembrar qualquer um a diferença entre simular sozinho efetivos exercícios em um tabuleiro (atividade que de lúdica pode ter muito, e de interessante, mas que em nada se assemelha a um jogo) e jogar uma partida por correspondência, em que cada lance deve ser pensado não só em relação às regras do jogo, mas, idealmente, como resposta ao lance prévio (situação real de jogo) e como medida mais efetiva para aquele oponente (colaborador?) específico (preparação real de jogo).

Não posso jogar sozinho.

Posso me divertir com as peças (itens lexicais, frases, língua), mas preciso de um outro para poder criar o jogo (significados, comunicação, linguagem). E em certos sentidos, muitos muito centrais, essa necessidade é mais relevante que a presença física de um outro. Tem vigor suficiente para transformar sua ausência efetiva em presença afetada, afetiva e, afinal, definitiva.

Não há sol a sós.

Só há jogo a dois.

O xadrez por correspondência, a carta, são nossos outros próprios. Que trazemos em cada eu.

Stephen Mackenna, para mim, será por definição interlocutor ausente. Para qualquer de nós.

Como qualquer escritor, contudo, ele deixou veios que nos vêm, e que nos permitem determinado contato. Continua falando conosco, ainda que, ao lermos seus textos, (especialmente suas traduções) sejamos um de muitos dos destinatários possíveis de cada uma daquelas mensagens.

Escrevo este texto, que não tem qualquer ilusão de atender aos rigores e aos modelos do artigo acadêmico mais típico, mas que se pretende, senão de fato carta, ao menos ensaio pessoal e direto, apenas com a finalidade de colmatar, em mim, aquela ausência. E, mais ainda, de verificar o quanto para Mackenna - escritor, jornalista, mas 
acima de tudo tradutor — a ideia da carta como resolução para o dilema ausência/presença na linguagem pode ter se mostrado o mais possível caminho.

Se cada texto (literário ou não) é mensagem, carta-aberta e carta aberta, destinado a infinidades de possíveis leitores, no mesmo momento em que a decisão da tradução se instaura, passam a valer as regras da correspondência. Reajo, passo a funcionar em réplica diante de uma enunciação prévia e definidora. Continuo mantendo a funcionalidade original do texto (minha tradução deverá também se caracterizar como carta-ao-mundo na mesma e precisa medida em que o original) mas ao mesmo tempo imbuo o texto de um elemento novo, de diálogo entre mim e seu produtor original.

Posso publicar a tradução de um romance como romance.

Mas fiz a tradução como quem escreve também uma carta a seu autor. Numa corespondência. A tradução é livro, o traduzir é correspondência.

Em inúmeros casos, em situação de tradução contratada ou não, essa réplica acaba gerando efetiva correspondência entre tradutor e autor, no que nada tem de novo, mas é na verdade concretização de um processo que, em tudo e por tudo, já se realizava antes mesmo da primeira carta (de papel?) enviada.

A situação contudo é mais marcada no caso da tradução de autores mortos.

McKenna traduziu outros autores, mas será sempre conhecido como o homem que produziu a primeira versão integral para o inglês dos seis grupos de nove tratados (enéadas, portanto) que Porfírio organizou a partir dos trabalhos do filósofo egípcioromano Plotino (205-270). Durante vinte anos de sua vida ele se dedicou ao trabalho de verter para um inglês de uma beleza absolutamente sem par o grego singular e o pensamento idiossincrático de um homem que viria a ser uma das influências centrais para toda uma corrente do pensamento místico ocidental. Durante vinte anos ele teve de aprender Plotino e o grego de Plotino, numa era em que o aparato crítico e analítico em torno do autor e do período nem remotamente se comparava ao que conhecemos hoje.

Durante esse período, McKenna sucumbiu ao que hoje seria possivelmente diagnosticado como transtorno bipolar, mas que na época era apenas descrito como grave neurastenia, que o deixava totalmente incapacitado por longos períodos, vítima dos "sonhos mais horrendos" e de uma prostração que o desfigurava.

Durante esse período em que seus diálogos mais profícuos se davam com um autor morto havia mais de um milênio e meio, e em que sua própria personalidade parecia provida de uma chave de liga/desliga, várias presenças/ausências o definiram e 
mantiveram. Sua mulher e sua longa doença (a constante expectativa do momento em que ela lhe faltaria), seus amigos em outro país (irlandês nascido na Inglaterra, ele morou na França, na Alemanha, na Rússia, na Suécia...), o benfeitor que teve a iniciativa de (e a persistência para) mantê-lo trabalhando no Plotino nos momentos em que sua confiança se abalava (e destinatário da carta que ainda traduzo e comento mais adiante), mas, acima de tudo, o grande Plotino.

Já se especulou (e não entro demasiado nessa questão) que a dedicação total de MacKenna a seu Plotino tenha tido um papel no colapso que deu o tom de seus últimos anos de vida. Porém, muito pelo contrário, a leitura, ainda que perfunctória, de suas cartas, por exemplo, deixa igualmente entrever o quanto Plotino pode ter-lhe sido uma espécie de tábua de salvação em mais de um momento.

Presente e ausente, nada mais claro que a possibilidade de que Plotino tenha sido carrasco e consolo.

Se McKenna viveu a presença de Plotino, entretanto, isso se deu de fato principalmente no momento do ato tradutório. A que não temos acesso. Se ele escreveu sua carta a Plotino, isso se deu efetivamente no ato do momento de tradução. A que não temos acesso. Temos, no entanto, graças aos esforços de Dodds, acesso àquela uma carta.

E por mais que tenha valor uma tal carta meramente como documento de investigação dos processos de tradução em que acreditava um estudioso dos clássicos helenísticos no começo do século $\mathrm{XX}$, acredito que sua efetiva contribuição é a demonstração da profunda relação tradutor-autor que pôde vir a desenhar aquela que já foi chamada de "a melhor tradução inglesa de um clássico grego".

É a ela que me volto agora.

\section{De presente, a carta}

O que se segue é uma versão completa (a primeira, imagino) da carta-manifesto de MacKenna a Debenham. Anoto a carta no que seja necessário, como esclarecimento de certas questões de contexto e da singular sintaxe de MacKenna. Mas acredito que os méritos do texto, dada sua precocidade, falem por si próprios, ao mesmo tempo em que demonstram a eternidade e a ciclicidade de inúmeros debates da história da tradução, especialmente pelo fato de que a "literalidade" é, afinal, o pomo da discórdia entre MacKenna e a Loeb. 
63, Merrion Square,

Dublin [Abril de 1919 $]^{2}$

Meu caro senhor Debenham, - Estranho: quando me deram seu envelope eu acabava de florear minha assinatura em uma carta para o senhor, basicamente tagarelices sobre o estado do Universo, mas em que lhe dizia que Plot. ${ }^{3}$ voltou a zumbir, já que está minha esposa (com quem Plot. jamais suspeitou estar relacionado) ao menos no caminho da total recuperação - ou seja, muito menos fantasmática, conquanto ainda muito titubeante e a-vital. Indo tudo bem, acrescentava, eu logo seria capaz de revisar a segunda e a terceira Enéadas, processo em que receberiam os últimos toques mágicos de elaboração. Então : - há alguns meses recebi uma carta que muito me deixou honrado, do pessoal da Loeb ${ }^{4}$, com basicamente o mesmo conteúdo da que lhe enviou o doutor Page $^{5}$. Respondi com franqueza: muito lisonjeado e tudo mais, mas que ainda não completei o trabalho para o senhor e não poderia, neste momento, ver como reformular minhas noções de tradução ${ }^{6}$; estava contudo disposto a permitir (com sua permissão) uma publicação com todas as correções que julgassem necessárias, desde que eles inserissem em local bem visível uma fórmula combinada que declarasse que o tradutor original não poderia ser considerado responsável, para bem ou para mal, por quaisquer sentenças ou interpretações que diferissem da edição Lee Warner. Não obtive resposta. Provavelmente não a mereci — não lamento esse fato.

É um cordial — um tônico — para mim que um homem simultaneamente tão distinto e pessoalmente tão encantador quanto o doutor Page fale de maneira tão prazerosa sobre meu trabalho - tenho de mostrar sua carta para meu pobre fantasminha em Kingstown ${ }^{7}$, que ganhará vida com o ânimo que isso lhe dará, e quisera ter a energia ou quiçá o tempo livre de copiá-la como uma espécie de pedigree para meus descendentes (colaterais). Mas sua concepção de tradução é polarmente distinta da minha: o que ele chama de elemento artístico \&c. ${ }^{8}$, eu chamo de simples veracidade - quer dizer, com a premissa de que veracidade não signifique uma espécie de transliteração mas sim a

\footnotetext{
${ }^{2}$ A datação é de Dodds, que registra a extrema inconstância e incerteza das informações presentes nas próprias cartas.

${ }^{3}$ Plotino, obviamente.

${ }^{4}$ A Loeb Classical Library, coleção editada pela Universidade de Harvard que circula até hoje e é até hoje referência com edições bilíngües de textos gregos e latinos, mas que naquele momento estava ainda começando.

${ }^{5}$ T.E.Page, junto com W.H.D. Rouse e Edward Capps, membro da primeira equipe editorial da coleção.

${ }^{6}$ Para se adequar ao projeto de "acessibilidade" da coleção Loeb.

${ }^{7}$ Hoje (depois da independência) Dún Laoghaire, Dublin.

8 Nos comentários às Enéadas de MacKenna. Esse lado artístico seria provavelmente uma das fragilidades para uma edição Loeb.
} 
transmissão da plenitude dos sentidos do autor, de sua ênfase, clima, Stimmung ${ }^{9}$ \&c. É claro que sei que certos tradutores, que trabalham com certos livros - os exemplares de Mackail $^{10}$, na Antologia, são um exemplo quase perfeito - podem gerar simultaneamente verdade para com o espírito (com beleza) e uma exatidão verbal quase total; mas isso está muito além de meu engenho. Ainda tenho comichões de reconstruir meu primeiro volume; mas precisamente no sentido contrário ao do doutor Page. Afinal, tenho há anos a obra quase toda traduzida literalmente e precisando de apenas alguns retoques para se tornar publicável segundo aquele ideal. Mas meus esforços, minha agonia, é precisamente o contrário - desliteralizar — em nome de uma veracidade mais elevada, em minha opinião.

É minha opinião que quando um estudante compreendeu Plot. como um todo, o sistema, e se acostumou aos estranhos empregos de palavras e à estrutura de sentenças e parágrafos de Plot., poucos autores são mais fáceis de traduzir daquela maneira chamada de literal; mas acho que nenhum outro autor que eu já tenha tocado é umoitavo tão difícil de transportar para outra língua. Todas as traduções ou fragmentos traduzidos existentes me parecem lamentavelmente injustos, a não ser pelos excertos ocasionais do doutor Caird ${ }^{11}$; não acredito que sequer o significado seja transmitido em qualquer momento (a não ser para os que conhecem a língua grega) nas outras traduções, a não ser na do doutor Caird e na minha. (Mueller e Kiefer ${ }^{12}$ me parecem tão deficientes quanto Bouillet ${ }^{13}$, ainda que de outras maneiras. E contudo eles se propõem ser "literais", e na acepção mais comum o são).

Sou tão completamente diferente (acredite em mim, com grande insegurança e o maior dos respeitos) do doutor Page, que até mesmo em um ponto secundário ${ }^{14}$, mas peculiarmente neste província, discordo toto coelo. Ou seja: se eu, pessoalmente, leio traduções do grego fico sempre com receio de estar lendo as idéias do tradutor, e não de seu autor, admirando os efeitos da paleta do tradutor, e não os do original: se tenho o texto grego em face fico tranqüilo; posso aumentar ou diminuir o colorido segundo o grego indica a meu temperamento que o tradutor exagerou ou se conteve demais nas cores, ergueu ou baixou o tom. Acho que a Loeb pode ter dado ${ }^{15}$ a seus tradutores uma

\footnotetext{
9 A palavra alemã significa, mais ou menos como o inglês mood, que traduzi por clima, algo como ambiente, mas pode também querer dizer afinação, no sentido musical do termo, graças a sua relação com o radical para a palavra voz.

10 John William Mackail, especialista em Virgílio e tradutor. A obra a que MacKenna se refere é provavelmente Select Epigrams from the Greek Anthology, de 1890.

${ }^{11}$ Edward Caird.

${ }^{12}$ H. F. Mueller e Otto Kiefer;

${ }^{13}$ Marie Nicolas Bouillet, tradutor francês de Plotino e Porfírio.

${ }^{14}$ i.e., a ideia de que uma edição bilíngüe obriga o tradutor a se manter mais próximo do original.

${ }^{15} \mathrm{Na}$ busca pela literalidade.
} 
liberdade muito mais arriscada do que se poderia permitir que o senhor Debenham me permitisse.

Leio muito grego em grego-latim, grego-francês, grego-alemão e grego-inglês como constante sugestão dos artifícios do métier de tradutor, e portanto me considero algo como uma autoridade neste ponto: a suma de minha posição seria a de que nada poderia ser mais útil aos clássicos do que traduções soberbamente livres, apoiadas, é claro, no mais rigoroso conhecimento, e acompanhadas do texto correto. $\mathrm{O}$ original providencia corretivo ou garantia; o leitor, acho eu, compreende as profundezas de seu grego ou de seu latim muito melhor graças à versão livre. Novamente penso em uma liberdade casta, uma liberdade baseada rigidamente em uma pré-servidão.

Constantemente me vejo incapaz de ler, incapaz de compreender traduções que pareceriam satisfazer as idéias comuns de "literalidade": mas me dêem uma tradução livre feita por um homem de alta erudição, e muitas vezes me vejo maravilhado ao descobrir que do meio da liberdade posso reconstruir o original grego quase verbatim. Em outras palavras, creio que se pode provar que uma boa tradução livre fica mais próxima do original que a maioria das traduções literais: é paradoxal, e no entanto é mais verdadeiro do que pensaria quem nunca tentou fazê-lo. Acrescentaria que tudo isso é de um ensaio há muito meditado e jamais escrito a respeito de traduções do grego em que acho que se pode demonstrar que a escola literal

1. Necessariamente, por princípio, elimina do domínio do tradutor territórios vastos e importantes, ou mesmo essenciais, da língua inglesa, de seus idiomatismos e palavras que tais, e

2. inclui enormidades de palavras, idiomatismos, e "ataques" em geral, que não pertencem mais ao inglês.

De modo que o inglês "literal" acaba sendo (1) o inglês de Liddel \& $\operatorname{Scott}^{16}$, ou (2) um inglês bastardo, mistura horrenda de elisabetanismos, jacobinismos, contos-defadismos, biblicismos e gíria moderna (não gíria lexical mas, o que é pior, sintática e de construção).

No todo, então: (1) Não posso eu mesmo reescrever minha tradução no sentido da Loeb. (2) Em nada me oponho (e muito me honra) que eles a usem, segundo suas ideias; mas nitidamente como não sendo minha, mas sim como a modificação ou correção que

\footnotetext{
${ }^{16} \mathrm{O}$ mais famoso dos dicionários de grego, publicado em 1843 e editado por Henry George Liddell, Robert Scott, Henry Stuart Jones e Roderick McKenzie. E já que falamos de ausências singulares, não custa lembrar que no mundo de língua inglesa o dicionário hoje é normalmente chamado de LSJ, para Liddell-Scott-Jones, descontado McKenzie. E também que aquele Liddell é o pai de Alice Liddell, imortalizada no "País das Maravilhas" de Lewis Carroll.
} 
fizeram eles da minha tradução (não tenho qualquer vaidade quanto a isso e não me incomodo nada de ser "corrigido" publicamente: na verdade fico atônito e algo chocado por não ter sido tratado assim ${ }^{17}$ ). (3) Não posso nem pensar no assunto, a não ser que eles esperem cerca de um ano até terminarmos a obra toda ${ }^{18}$.

Espero não ter sido longo demais. Leia-me aos pedaços; como que uma pílula depois das refeições, até ter lido tudo.

O senhor já leu God the invisible king de Wells ${ }^{19}$ ? Creio que Wells odeie Plot, (de orelhada, ao menos) mas mesmo assim não se afasta dele. Achei o livro sugestivo e em certos trechos edificante, "construinte".

Cordiais saudações

S.M.K.

P.S, Devolvo as cartas sem falha amanhã ou depois de amanhã, depois de ter reanimado com elas meu fantasma.

\section{Ausências presentes, uma carta a MacKenna}

Uma liberdade baseada em uma pré-servidão.

Então.

A autonomia que se funda em primeira dependência.

Um discurso pleno que depende.

A tradução para MacKenna na carta de MacKenna era efetivamente da natureza da carta aqui traduzida. Ou da escrita de cartas.

Um discurso de um eu que se sentia tão plenamente carregado pelo outro, seu motivo e seu destino, que se via não apenas no direito mas de fato na obrigação de ser mais plenamente um eu eticamente responsável por um discurso todo seu mas, como todos, fruto de um outro.

Traduzo aqui uma carta gerando uma outra carta. No próprio processo.

Ser mais eu é permitir o único acesso verdadeiro ao outro que me instila.

Daí talvez a tensa relação de dor e salvação que seu mergulho na obra e no texto de Plotino possa ter suscitado.

\footnotetext{
${ }^{17}$ A ausência de uma "recepção" para seu trabalho incomodou bastante MacKenna.

${ }^{18} \mathrm{O}$ que levaria na verdade ainda onze anos.

${ }^{19}$ Tratado sobre uma "religião do futuro", de H.G. Wells.
} 
O homem que declarou que Plotino lhe gerava "um pequeno fogo dos infernos cerebral" era afinal o mesmo que afirmava sentir que mesmo assim haveria de "publicar sua grande obra como contribuição de minha pequena vida" ${ }^{20}$.

O mesmo tradutor que confessava ter assumido "francamente, algo que estava além de minha capacidade" ${ }^{21}$ era quem dizia "me parece que devo ter nascido para ele, e que de alguma forma, em algum momento, eu devo tê-lo traduzido elegantemente." ${ }^{22}$ Um homem no entanto que, mesmo nos momentos mais difíceis de seu trabalho, continuava sabendo que se tornava "cada vez mais profundamente um discípulo espiritual de Plotino.",23

E não só isso, pois o escritor que já havia sido considerado o melhor prosador da língua inglesa ${ }^{24}$ deixou uma obra fundamental em que escreve os textos de um outro, 1600 anos mais anterior a ele. E alguém que se considerava acima de tudo um causeur, um conversador que podia "dizer mais em cinco minutos com minha pequena língua que com a maior caneta-tinteiro do mundo ${ }^{25}$ " e que dizia a seu editor que "nunca consegui agir como um ser razoável, a não ser em tête à tête ${ }^{26}$ ficou por escrito na história da literatura inglesa, e é lido aqui, neste trabalho precisamente pela chave da presença/ausência, por alguém que jamais teria tido o prazer de conversar com ele.

Mas que usurpa agora o direito de ler suas cartas.

E, ausência final, estamos discutindo as concepções de tradução de MacKenna a partir de uma carta em que, suma ironia, ele aponta para a inexistência de um ensaio em que discorreria mais diretamente sobre elas.

Stephen MacKenna, que não existe mais, resiste como Plotino, que não mais existia. E existimos todos em correspondência uns com os outros. Como réplicas de um mesmo discurso.

Presentes como presentes ofertados. E ofertados porque recebidos. Igualmente.

Tradutores, vivemos cada um a sua maneira os paradoxos de autoria e reprodução, originalidade e fidelidade, discurso e mecanicidade. Geramos cartas abertas sucedâneas de outras. Reeditamos processos de fundação (curioso o apego de

\footnotetext{
${ }^{20}$ Dodds, p.48.

${ }^{21}$ Dodds, p.64.

${ }^{22}$ Entrada de diário, 5 de dezembro de 1907, constante de Dodds, p.114.

${ }^{23}$ Dodds, p.69.

${ }^{24}$ Por Sir John Squire, segundo Dodds, p.82.

${ }^{25}$ Em carta a AE.

${ }^{26}$ Em carta a Debenham.
} 
MacKenna por metáforas de "construção") sem substituir uma coisa pela outra (como poderia pensar algum senso comum), mas definitivamente acrescentando uma camada ao processo, aos discursos, ao jogo de presenças.

Presentes, ocupamos o lugar de autores ausentes.

Cada livro não-traduzido, uma carta perdida. Uma possibilidade impossibilitada.

Ausentes para a maioria dos leitores e da crítica, somos a única presença que lhes é dado conhecer.

Porque existe, enfim, essa maneira.

Talvez a única.

De combinar solidão e boa companhia.

Traduzir.

Escrever ininterruptamente uma carta como resposta a algo que nos foi dito por vezes em outro milênio, que será lida talvez por um co-respondente um século distante.

Co-responder-se.

Traduzir.

\section{Referências bibliográficas}

DODDS, E. R. Journal and Letters of Stephen MacKenna. Londres: Constable, 1936. Disponível em [http://www.archive.org/details/journalandletter014916mbp] (acesso em 08/09/10)

GIFFORD, Don. Ulysses annotated. Berkeley: University of California Press, 1989.

JOYCE, James. Ulysses. Londres: Penguin, 1959.

PLOTINO. The Enneads (trad. S. MacKenna). Chicago:Encyclopaedia Britannica, c1952.

STOPPARD, Tom. Arcadia. Londres: Faber and faber, 1994.

WITTGENSTEIN, Ludwig. Philosophical Investigations (trad. G.E.M. Anscombe). Hoboken, NJ: Wiley-Blackwell, 1991. 